\title{
Race, Socioeconomic Status, and Age: Exploring Intersections in Preterm Birth Disparities among Teen Mothers
}

\author{
Sheryl L. Coley, ${ }^{1,2}$ Tracy R. Nichols, ${ }^{1}$ Kelly L. Rulison, ${ }^{1}$ Robert E. Aronson, ${ }^{1,3}$ \\ Shelly L. Brown-Jeffy, ${ }^{4}$ and Sharon D. Morrison ${ }^{1}$ \\ ${ }^{1}$ Department of Public Health Education, University of North Carolina at Greensboro, Greensboro, NC 27402, USA \\ ${ }^{2}$ Center for Women's Health and Health Disparities Research, University of Wisconsin-Madison, Madison, WI 53705, USA \\ ${ }^{3}$ Public Health Program, Taylor University, Upland, IN 46989, USA \\ ${ }^{4}$ Department of Sociology, University of North Carolina at Greensboro, Greensboro, NC 27402, USA
}

Correspondence should be addressed to Sheryl L. Coley; scoley2@wisc.edu

Received 27 September 2014; Revised 16 January 2015; Accepted 18 January 2015

Academic Editor: Kathryn Kost

Copyright (C) 2015 Sheryl L. Coley et al. This is an open access article distributed under the Creative Commons Attribution License, which permits unrestricted use, distribution, and reproduction in any medium, provided the original work is properly cited.

\begin{abstract}
Few studies have examined disparities in adverse birth outcomes and compared contributing socioeconomic factors specifically between African-American and White teen mothers. This study examined intersections between neighborhood socioeconomic status (as defined by census-tract median household income), maternal age, and racial disparities in preterm birth (PTB) outcomes between African-American and White teen mothers in North Carolina. Using a linked dataset with state birth record data and socioeconomic information from the 2010 US Census, disparities in preterm birth outcomes for 16,472 teen mothers were examined through bivariate and multilevel analyses. African-American teens had significantly greater odds of PTB outcomes than White teens $(\mathrm{OR}=1.38,95 \%$ CI 1.21, 1.56). Racial disparities in PTB rates significantly varied by neighborhood income; PTB rates were 2.1 times higher for African-American teens in higher income neighborhoods compared to White teens in similar neighborhoods. Disparities in PTB did not vary significantly between teens younger than age 17 and teens ages 17-19, although the magnitude of racial disparities was larger between younger African-American and White teens. These results justify further investigations using intersectional frameworks to test the effects of racial status, neighborhood socioeconomic factors, and maternal age on birth outcome disparities among infants born to teen mothers.
\end{abstract}

\section{Introduction}

Disparities in birth outcomes among mothers in different racial, age, and socioeconomic groups continue to present a critical health concern in the United States. Specifically, previous research on various US populations identified persistent disparities in adverse birth outcomes based on maternal characteristics, which include race as Black or AfricanAmerican, younger maternal age (younger than 17 years old), and low socioeconomic status $[1,2]$. Nationwide, AfricanAmerican mothers have a greater prevalence of adverse birth outcomes than White mothers [3], and previous studies have identified these racial disparities across all maternal age groups $[4,5]$. These studies also consistently have demonstrated greater prevalence of low birth weight (weight less than 2500 grams), preterm birth (birth prior to 37 weeks gestation), and neonatal mortality outcomes among infants born to teen mothers in comparison to adult mothers [5-8]. In addition, greater proportions of adverse birth outcomes and associated disparities were found among mothers in environments of lower socioeconomic status in comparison to mothers residing in higher socioeconomic environments $[9,10]$.

The continued importance of examining preterm birth (PTB) outcomes rests on the increased risk of infant mortality for preterm infants before they turn one year old. The US consistently ranks behind other industrialized countries in infant mortality rates [11], and currently PTB is one of the leading causes of infant death overall in the US [3]. Despite this critical nature of PTB, few studies have examined differences in PTB specifically between African-American and White teen mothers. Instead, studies in PTB disparities mostly focused 
on adult mothers. Rates of PTB are consistently higher among mothers younger than 17 compared to adult mothers [2] and higher proportions of African-American mothers of younger ages have infants compared to mothers of other races [12]. As a result, the assumption prevails that maternal age sufficiently explains racial disparities in PTB and other adverse outcomes among infants born to teen mothers. This assumption subsequently limits investigation of other factors, and few studies have specifically examined the interplay of race and socioeconomic factors in associations with adverse birth outcomes among teen mothers $[13,14]$.

More current studies have examined health disparities and associated factors using intersectional frameworks [1519]. As theoretical perspectives for public health, intersectional frameworks incorporate several principle tenets [20]: (1) multiple social identities intersect and are interdependent; (2) members of historically oppressed or marginalized groups are examined within their context; (3) multiple social identities at the individual level intersect with multiple level structural factors to contribute to disparities in health outcomes; and (4) social categories are considered equally important in their influence. Using intersectional frameworks can allow researchers to explore birth outcome disparities among teen mothers through examining relationships between race and socioeconomic status as "historically created relationships of differential distribution of resources, privilege, and power, of advantage and disadvantage" [21] to identify where disparities exist within disadvantaged groups of teen mothers and the context that may contribute to these disparities.

This study examined disparities in PTB between AfricanAmerican and White teen mothers using an intersectional socioecological framework. To date, no studies previously examined racial disparities in birth outcomes among teen mothers using intersectional frameworks. Given the persistence of racial disparities in birth outcomes among teen mothers in the US, findings from this study can help to identify target high-risk subgroups of teen mothers for prenatal and preconception health intervention and subsequently increase positive birth outcomes in these subgroups.

\section{Theoretical Framework and Research Questions}

This study incorporated an intersectional framework in the context of previous socioecological perspectives [2224]. Socioecological frameworks posit that multiple circumstances at the intrapersonal, interpersonal, community, institutional, and policy levels influence health outcomes. Using this combination of perspectives can provide deeper insight into relationships between factors that contribute to health outcomes at different levels as well as the amount of variance attributed at each level under examination [25]. Through this framework, this study investigated the intersection of race as an intrapersonal construct with socioeconomic factors at the community level to affect PTB outcomes among teen mothers.

Although previous research has consistently identified PTB disparities between African-American and White teen mothers, these studies have not identified which groups within African-American teens experience more disparate outcomes. Based on the intersectionality tenets previously described, the goal of this study was to identify these subgroups through the assessment of race, socioeconomic status, and maternal age as moderators of PTB. The research team examined intersecting relationships between race and socioeconomic status in explaining disparities in birth outcomes through the first research question: does neighborhood socioeconomic status moderate racial differences in PTB of infants born to teen mothers? Given previous research that younger mothers (under 17 years old) experience greater risk of adverse birth outcomes $[1,2]$, the second research question involved examining intersecting relationships among race, socioeconomic status, and maternal age: does neighborhood socioeconomic status moderate racial differences in PTB differently between younger and older teen mothers? The research team proposed that African-American teen mothers' identities based on race and maternal age uniquely intersected with socioeconomic status, and these intersections contributed to disparities in greater proportions of PTB among infants born to African-American teen mothers in comparison to White teen mothers.

\section{Methods}

3.1. Data Sources. This cross sectional study analyzed birth record data from the North Carolina State Center of Health Statistics (NCSCHS) for the years 2010-2011. The NCSCHS approved the use of these data for this study, and the authors' institutional review board provided exemption for this study because no interaction occurred with human participants during this secondary data analysis. Hospitals and other birth centers across the state collected these data based on 2003 US birth certificate standards which ensure accuracy in data reporting [26]. Mothers' street addresses were geocoded to census-tract identification numbers using ArcGIS 10.0 (Redlands, CA: Environmental Systems Research Institute) and the Federal Financial Institutions Examination Council geocoder. Geocoded cases were subsequently linked by the census-tract identification numbers to statistics from the 2007-2011 American Community Survey and the 2010 US Census.

3.2. Study Sample. Figure 1 illustrates the sample selection process for this study. Approximately 243,000 mothers gave birth in 2010-2011 in the state [12, 27, 28], and 23,383 infants were born to teen mothers ( $10 \%$ of all births). Notably, the percentage of all births to teen mothers was higher among African-American mothers (14.0\%) compared to White mothers $(5.7 \%)$. This study included teen mothers who had the following characteristics: racial and ethnic status as non-Hispanic African-American or White, United States birthplace, maternal age 19 years and under at the date of their infants' birth, North Carolina residency, and live birth delivery of singleton infants at gestational ages of 20 weeks or more. Hispanic and foreign-born mothers were excluded because the socioeconomic considerations of ethnicity might 


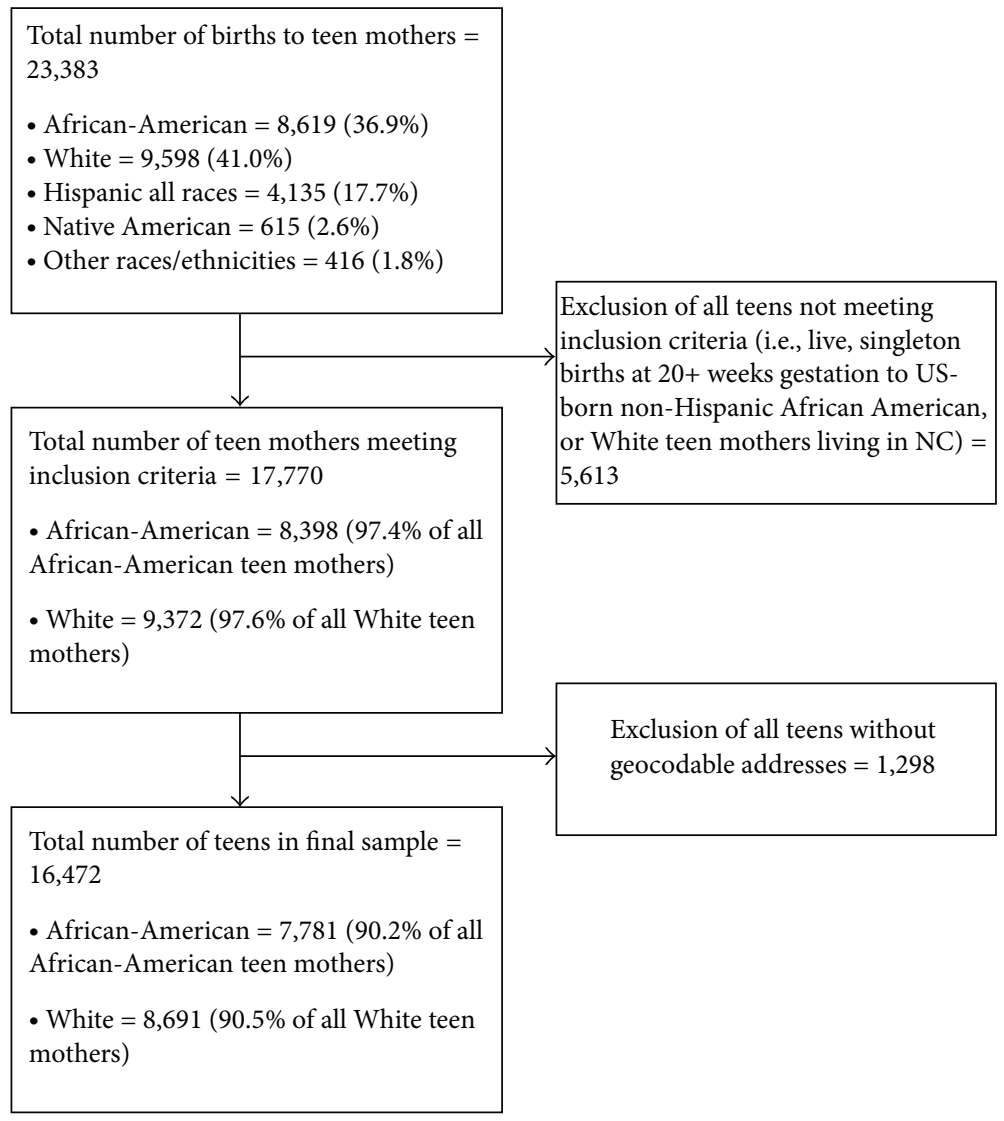

FIgURE 1: Sample selection for study.

confound the comparison of racial groups. Mothers of other races were also excluded because the proportion of teen mothers in these groups was too small for meaningful comparisons (less than 3\% each). Analyses also excluded 1,298 mothers with nongeocodable addresses, which resulted in the final study sample of 16,472 teen mothers ( $93 \%$ of all eligible mothers). Descriptive analyses indicated that cases that could not be geocoded did not significantly differ from the study sample in maternal characteristics or birth outcomes.

The mothers included in this sample resided in 1,991 out of 2,183 land-based census-tracts across North Carolina (91.2\% of all land-based census tracts). Given the small amounts of teen mothers per census-tract ( $n=1-30$ mothers in each tract), census-tracts were used to operationalize neighborhood units for this study instead of census-blocks. These teens lived in census-tracts with a diverse range of racial concentration of African-American residents (95\% CI $=1.2,81.3$ ). Approximately $41 \%$ of these teens lived in censustracts where African-Americans comprise between 25\%-75\% of total residents. Thus, a substantial proportion of these teens resided in census-tracts where the African-American racial composition exceeded the state and national average of African-American residents (21.5\% and $12.6 \%$ resp.) [29].

3.3. Study Measures. This study examined PTB as the dependent birth outcome variable and race and maternal age as the individual-level independent variables. PTB was defined as births that occurred prior to 37 weeks gestation per previous obstetric guidelines [2]. Analyses included race as a dichotomous variable (African-American versus White). Consistent with past literature that examined birth outcomes between age groups of teen mothers [2, 6, 7], maternal age was coded as a dichotomous variable (younger than 17 years old versus 17-19 years old).

Income is the most frequently used socioeconomic variable in past research $[16,17]$ because of the influence of income on access to health services (i.e., prenatal care) and general resources. Consistent with past studies [30], neighborhood socioeconomic status was operationalized as census-tract median household income from the US Census. Following prior research guidelines for teen samples [31] and previous research that has examined socioeconomic associations with birth outcome disparities between adult mothers [32], teens in the lowest income quartile comprised the "low" income group, teens in the middle $50 \%$ quartiles comprised the "middle" income group and teens in the highest income quartile comprised the "high" median income group. The high income group represented the referent category for all analyses because the research team assumed that teens in the high income group would have more opportunity for resources and subsequently have better health status, prenatal behaviors, and birth outcomes. 
3.4. Analysis Plan. Descriptive and bivariate analyses included chi-square tests and independent sample $t$-tests to test for differences in income levels and maternal age. Chi-square tests were also completed to test for differences in PTB rates across race, maternal age, and income levels. SPSS v.21 [33] was used to compute all descriptive and bivariate analyses.

Past research generally applied intersectional theoretical approaches by examining interactions between variables [16, $19,25,34,35]$. This study replicated previous intersectional research with the use of two-way and three-way interactions to test whether neighborhood socioeconomic status significantly moderated relationships between racial status and birth outcomes and relationships between maternal age and birth outcomes. Significant interactions were probed through omnibus interaction tests and examination of $95 \%$ confidence intervals [36-38].

Multilevel models [39] identified cross-level interactions between variables at the individual level (race, maternal age) and variables at the neighborhood level (income). Despite the usefulness of multilevel models, few studies incorporate these analyses to examine health disparities between racial and ethnic groups [40, 41]. By examining cross-level interactions, multilevel analyses treat individual characteristics and neighborhood characteristics at their appropriate ecological levels to identify relationships among these characteristics. All multilevel models were computed through the use of HLM 7.01 [42].

Binomial hierarchical generalized linear models were computed to examine associations with PTB. The models assess the PTB odds as a function of race and maternal age as individual-level covariates and income as the neighborhoodlevel covariate. Models 1-3 separately assessed race, median household income level, and maternal age to identify significant differences in PTB relative to these characteristics. An additive model (Model 4) tested the independent contributions of race, income, and maternal age. Next, two-way interaction models (Models 5-7) tested the individual-level interaction between race and maternal age and the crosslevel interactions between race and income and maternal age and income. The final three-way interaction Model 8 tested the cross-level interactions between race, maternal age, and income. Specifications for the final model are provided in the following equations [39]:

Level 1:

$$
\begin{aligned}
& \operatorname{Prob}(\operatorname{PTB}=1 \mid \beta)=\phi, \\
& \log \left[\frac{\phi}{(1-\phi)}\right]=\eta \\
& \eta=\beta_{0}+\beta_{1}(\text { race })+\beta_{2}(\text { age })+\beta_{3}(\text { race } \times \text { maternal age })
\end{aligned}
$$

Level 2:

$$
\begin{aligned}
& \left.\beta_{0}=\gamma_{00}+\gamma_{01} \text { (low income }\right)+\gamma_{02}(\text { middle income })+u_{0}, \\
& \left.\left.\beta_{1}=\gamma_{10}+\gamma_{11} \text { (low income }\right)+\gamma_{12} \text { (middle income }\right)+u_{1},
\end{aligned}
$$

TABLE 1: Demographic characteristics of study sample [mean \pm standard deviation or $N(\%)]$.

\begin{tabular}{lcc}
\hline & $\begin{array}{c}\text { African-American } \\
(n=7781)\end{array}$ & $\begin{array}{c}\text { White } \\
(n=8691)\end{array}$ \\
\hline Median income (US Dollars) & $\$ 37,113 \pm \$ 14,690$ & $\$ 44,081 \pm \$ 13,192$ \\
Low $(<\$ 31,389)$ & $2986(38.4 \%)$ & $1138(13.1 \%)$ \\
Middle $(\$ 31,389-\$ 48,466)$ & $3287(42.2 \%)$ & $4942(56.9 \%)$ \\
High $(>\$ 48,466)$ & $1508(19.4 \%)$ & $2611(30.0 \%)$ \\
Maternal age (years) & $17.87 \pm 1.26$ & $18.08 \pm 1.09$ \\
Age $<17$ & $1145(14.7 \%)$ & $852(9.8 \%)$ \\
Age $17-19$ & $6636(85.3 \%)$ & $7839(90.2 \%)$ \\
\hline
\end{tabular}

All differences between racial categories were significant at $P<0.001$.

$$
\begin{aligned}
& \left.\left.\beta_{2}=\gamma_{20}+\gamma_{21} \text { (low income }\right)+\gamma_{22} \text { (middle income }\right)+u_{2}, \\
& \left.\left.\beta_{3}=\gamma_{30}+\gamma_{31} \text { (low income }\right)+\gamma_{32} \text { (middle income }\right)+u_{3} .
\end{aligned}
$$

Chi-square likelihood ratio tests [43] assessed model fit when comparing the interaction models with the oneindependent-variable models in accordance with the hypothesis that the interactions between race, income, and maternal age contributed to PTB disparities in this sample beyond the contribution of any singular independent variable. Two-sided $P$ values $<0.05$ determined significance for all analyses.

\section{Results}

As presented in Table 1, bivariate analyses indicated significant differences in neighborhood income and maternal age between the two racial groups. More African-American teens resided in low income environments than White teens, whereas greater proportions of White teens resided in middle and high income environments $\left(\chi^{2}=1410.35, P<0.001\right)$. African-American teens were also significantly younger than White teens at the time of childbirth $(t=11.50, P<0.001)$.

The chi-square tests presented in Table 2 indicated differences in PTB based on the intersections among race, income and maternal age. Similar to previous studies, infants born to African-American teens had a significantly greater proportion of PTB than infants born to White teens $\left(\chi^{2}=\right.$ $19.55, P<0.05$ ). For the overall sample (not shown), no significant differences in PTB rates were found between younger and older teen mothers or between mothers in the three income groups. Tests within each age group indicated racial disparities for both younger teen mothers $\left(\chi^{2}=8.13\right.$, $P<0.01)$ and older teen mothers $\left(\chi^{2}=12.55, P<0.001\right)$. By contrast, tests within each income group indicated significant racial disparities only between African-American and White teens in the high income group $\left(\chi^{2}=28.16, P<0.05\right)$; no statistically significant racial disparities in PTB were found among mothers in the other two income groups. Notably, the observed proportion of PTB for African-American teens in high income neighborhoods was higher than both AfricanAmerican teens in lower and middle income groups and for White teen moms in all income groups. Tests within each 
TABLE 2: Chi-square analyses testing for racial differences in PTB rates stratified by maternal age and income.

\begin{tabular}{|c|c|c|c|c|}
\hline & Full sample $(n=16,472)$ & African-American $(n=7781)$ & White $(n=8691)$ & Chi-square $^{\mathrm{a}}$ \\
\hline Overall PTB rate & $9.6 \%$ & $10.7 \%$ & $8.7 \%$ & $19.55^{* * *}$ \\
\hline Low $(<\$ 31,389)$ & $10.2 \%$ & $10.4 \%$ & $9.5 \%$ & 0.77 \\
\hline Middle $(\$ 31,389-\$ 48,466)$ & $9.5 \%$ & $10.1 \%$ & $9.1 \%$ & 2.56 \\
\hline High $(>\$ 48,466)$ & $9.4 \%$ & $12.5 \%$ & $7.5 \%$ & $28.16^{* * *}$ \\
\hline Age $<17$ years & $10.5 \%$ & $12.2 \%$ & $8.2 \%$ & $8.13^{* *}$ \\
\hline Age 17-19 & $9.5 \%$ & $10.5 \%$ & $8.7 \%$ & $12.55^{* * *}$ \\
\hline Low income, age $<17$ years & $10.9 \%$ & $11.5 \%$ & $8.9 \%$ & 0.75 \\
\hline Low income, age 17-19 & $10.0 \%$ & $10.2 \%$ & $9.6 \%$ & 0.32 \\
\hline Middle income, age $<17$ years & $10.5 \%$ & $12.3 \%$ & $8.7 \%$ & 3.02 \\
\hline Middle income, age 17-19 & $9.4 \%$ & $9.8 \%$ & $9.1 \%$ & 0.33 \\
\hline High income, age $<17$ years & $9.9 \%$ & $13.5 \%$ & $7.0 \%$ & $5.53^{*}$ \\
\hline High income, age 17-19 & $9.3 \%$ & $12.4 \%$ & $7.6 \%$ & $22.71^{* * *}$ \\
\hline
\end{tabular}

Significant differences between racial categories, ${ }^{*} P<0.05,{ }^{* *} P<0.01,{ }^{* * *} P<0.001$.

${ }^{a}$ Chi-square statistics reflect tests for racial differences only. Other analyses for the full sample (not shown) found no significant differences between younger and older mothers $\left(\chi^{2}=1.90, P=0.17\right)$ or between mothers in each of the three income groups $\left(\chi^{2}=1.77, P=0.41\right)$.

TABLE 3: PTB analyses for race, income, and maternal age multilevel models [OR (95\% CI)].

\begin{tabular}{|c|c|c|c|c|}
\hline & Model 1: race alone & Model 2: income alone & Model 3: age alone & Model 4: additive model \\
\hline Intercept & $0.11(0.10,0.11)^{* * *}$ & $0.10(0.10,0.11)^{* * *}$ & $0.11(0.10,0.11)^{* * *}$ & $0.11(0.10,0.11)^{* * *}$ \\
\hline African-American (AA) & $1.38(1.21,1.56)^{* * *}$ & & & $1.36(1.20,1.56)^{* * *}$ \\
\hline White (referent group) & - & & & - \\
\hline Low income & & $1.09(0.95,1.27)$ & & $1.10(0.96,1.26)$ \\
\hline Middle income & & $1.02(0.90,1.15)$ & & $1.02(0.91,1.14)$ \\
\hline High income (referent group) & & - & & - \\
\hline Age $<17$ & & & $1.15(0.98,1.34)$ & $1.15(0.99,1.32)$ \\
\hline Age 17-19 (referent group) & & & - & - \\
\hline \multicolumn{5}{|l|}{ Random variance } \\
\hline Intercept (SD) & $0.03(0.17)$ & $0.03(0.18)$ & $0.03(0.18)$ & $0.03(0.17)$ \\
\hline \multicolumn{5}{|l|}{ Statistics comparisons } \\
\hline$-2 * \log$ likelihood & 46126.98 & 46598.64 & 46317.62 & 45586.18 \\
\hline
\end{tabular}

${ }^{*} P<0.05,{ }^{* *} P<0.01,{ }^{* * *} P<0.001$.

age and income group indicated that racial disparities for mothers in high income neighborhoods persisted for both younger and older teen mothers, with a higher observed racial disparity in PTB rates for mothers younger than age 17 compared to mothers ages 17-19.

Table 3 presents the results for the multilevel models which are consistent with the chi-square results. Among the three variables, only race had significant differences in odds of PTB when assessed alone. In Model 1, African-American teens had significantly greater odds of PTB outcomes than White teens $(\mathrm{OR}=1.38,95 \% \mathrm{CI} 1.21,1.56)$. In contrast, no significant differences in PTB were identified with respect to median household income (Model 2) or maternal age (Model 3). The additive model (Model 4) indicated that racial differences remained significant and unchanged when controlling for income and age, whereas no significant main effects were found with income or age in this model.

Table 4 presents results from the interaction multilevel Models 5-8. To facilitate interpretation of the results of the interaction terms in these models, separate models stratified by income and age were run. In Model 5, neighborhood median household income moderated the relationship between race and odds of PTB as indicated by the significant two-way race $\times$ median household income interactions. These significant interactions indicated that racial disparities in PTB were significantly smaller in both low and middle income neighborhoods, compared to racial disparities in higher income neighborhoods. According to these incomestratified results, African-American teens in high income neighborhoods ( $\mathrm{OR}=2.11,95 \%$ CI 1.61, 2.76) and middle income neighborhoods ( $\mathrm{OR}=1.25,95 \%$ CI 1.01, 1.54) had significantly greater odds of PTB than White teens in similar neighborhoods. African-American teens in low-income neighborhoods did not have significantly greater odds of PTB than their White counterparts $(\mathrm{OR}=1.03,95 \%$ CI $0.74,1.43)$.

In Models 6-8, racial and neighborhood income differences in odds of PTB did not significantly vary by maternal age group, as indicated by the nonsignificant interactions 
TABLE 4: Intersectional analyses for PTB multilevel models with interaction terms [OR (95\% CI)].

\begin{tabular}{|c|c|c|c|c|}
\hline & $\begin{array}{c}\text { Model 5: addition of race } \times \\
\text { income interactions }\end{array}$ & $\begin{array}{l}\text { Model 6: addition of } \\
\text { race } \times \text { age interaction }\end{array}$ & $\begin{array}{l}\text { Model 7: addition of age } \\
\times \text { income interactions }\end{array}$ & $\begin{array}{c}\text { Model 8: addition of race } \times \\
\text { income } \times \text { age interactions }\end{array}$ \\
\hline Intercept & $0.10(0.10,0.11)^{* * *}$ & $0.11(0.10,0.11)^{* * *}$ & $0.11(0.10,0.11)^{* * *}$ & $0.10(0.10,0.11)^{* * *}$ \\
\hline African-American (AA) & $1.49(1.29,1.71)^{* * *}$ & $1.33(1.17,1.51)^{* * *}$ & & $1.40(1.23,1.60)^{* * *}$ \\
\hline White (referent group) & - & - & & - \\
\hline Low income & $1.13(0.98,1.31)$ & & $1.10(0.95,1.27)$ & $1.13(0.99,1.29)$ \\
\hline Middle income & $1.05(0.92,1.18)$ & & $1.02(0.90,1.15)$ & $1.05(0.93,1.17)$ \\
\hline High income (referent group) & - & & - & - \\
\hline AA $\times$ low income & $0.50(0.33,0.74)^{* *}$ & & & $0.50(0.35,0.72)^{* * *}$ \\
\hline $\mathrm{AA} \times$ middle income & $0.59(0.43,0.82)^{* *}$ & & & $0.61(0.45,0.89)^{* *}$ \\
\hline Age $<17$ & & $0.97(0.78,1.21)$ & $1.14(0.97,1.36)$ & $0.94(0.75,1.19)$ \\
\hline Age 17-19 (referent group) & & - & - & - \\
\hline AA status $\times$ Age $<17$ & & $1.31(1.00,1.71)$ & & $1.35(0.98,1.84)$ \\
\hline Age $<17 \times$ low income & & & $1.01(0.67,1.53)$ & $1.15(0.60,2.20)$ \\
\hline Age $<17 \times$ middle income & & & $1.00(0.66,1.49)$ & $1.15(0.67,1.97)$ \\
\hline AA $\times$ Age $<17 \times$ low income & & & & $0.81(0.36,1.83)$ \\
\hline AA $\times$ Age $<17 \times$ middle income & & & & $0.85(0.40,1.78)$ \\
\hline \multicolumn{5}{|l|}{ Random variance } \\
\hline Intercept (SD) & $0.03(0.17)$ & $0.03(0.18)$ & $0.03(0.18)$ & $0.04(0.19)$ \\
\hline \multicolumn{5}{|l|}{ Statistics comparisons } \\
\hline$-2 * \log$ likelihood & 46230.62 & 45036.9 & 46329.9 & 45120.22 \\
\hline
\end{tabular}

that include maternal age. The two-way race $\times$ maternal age interaction was marginally nonsignificant (Model 6). Agestratified analyses indicated that older African-American teens had significantly higher odds of PTB compared to older White teens ( $\mathrm{OR}=1.33,95 \%$ CI $1.15,1.55)$. Younger AfricanAmerican teens did not have significantly higher odds of PTB than older White teens ( $\mathrm{OR}=1.35,95 \%$ CI $0.86,2.15)$. The nonsignificant two-way maternal age $\times$ income interactions (Model 7) indicate that age differences in odds of PTB do not significantly vary by income level. Income-stratified analyses confirmed the lack of significant differences between younger and older teens across all income groups. When all interaction terms were included together (Model 8), the race $\times$ income interactions remained significant and unchanged. No other significant two-way or three-way interactions with maternal age were present for the interaction Model 8.

In sum, racial disparities in PTB persisted in the context of maternal age and neighborhood income level with the greatest disparities found between African-American and White teens in living in the highest income neighborhoods. Neighborhood income significantly moderated racial differences in the odds of PTB, although neighborhood income did not have significant relationships with PTB odds when assessed alone nor with maternal age. Therefore, neighborhood income was associated with significant differences in PTB outcomes only in the context of race. Racial disparities were also present regardless of the mothers' age group, and the moderating effects of neighborhood income on racial disparities in PTB odds did not vary by maternal age group.

\section{Discussion}

Consistent with past literature that has found racial disparities in birth outcomes among teen mothers $[13,14]$, rates of PTB were higher for African-American teen mothers living in North Carolina compared to White teen mothers. More importantly, the modifying relationships of neighborhood income suggested that race intersects with socioeconomic status to affect PTB outcomes. Although the general pattern of results suggested that African-American teen mothers had the highest rates of $\mathrm{PTB}$ across all income groups, rates of PTB were approximately 2.1 times higher for African-American teen mothers in high income neighborhoods compared to White teen mothers in similar neighborhoods. Thus, the greatest disparities were found between African-American and White teen mothers in high income neighborhoods. Notably, the magnitude of these results were on the lower end of disparities often found among adult mothers; rates of poor birth outcomes are often 2 to 3 times higher among AfricanAmerican adult women than among White adult women $[4,32,44]$. The larger disparities among adult mothers could stem from the cumulative exposure that AfricanAmerican adult mothers would have to life circumstances in a "weathering" life course process [44]. Alternatively, the smaller racial disparity could stem from all teens being at increased risk of PTB compared to adults, leaving race to play a smaller (albeit still notable) role among teens.

Our findings are also consistent with previous studies that focused on adult mothers. In the current study, 
African-American teens in the highest income neighborhoods had the highest observed proportions of PTB among all teens in the sample, including White teens in the lowest income neighborhoods. This finding parallels previous study results in which African-American women with more education and higher income had worse health outcomes and higher rates of infant mortality than White women of lower socioeconomic status $[16,17,32]$. Future studies should explore whether other community factors, such as racial concentration of neighborhoods, may explain this phenomenon. For example, neighborhoods of higher socioeconomic status often have greater access to resources but lower proportions of African-American residents. As a result, African-American teen mothers may experience less social support, higher levels of stigmatization, and consequently greater levels of stress in these neighborhoods as hypothesized for adult AfricanAmerican mothers [45]. Consistent with this possibility, previous research found a positive correlation between censustract proportions of African-American residents and infant birth weight among African-American teen mothers [13]. Future studies should therefore explore the intersections between race and socioeconomic status by assessing racial concentration and other community-level factors.

The findings from our study differ from previous studies with teen mothers in several ways. Our finding that the PTB disparity between African-American and White teens was statistically significant in the highest and middle income neighborhoods differs from Partington et al. [14], who found that racial disparities in PTB among teen mothers became nonsignificant after controlling for income. Comparing the two studies suggests that racial disparities in birth outcomes could differ by geographic location. Differences with this previous study could stem from our use of a Southeastern statewide sample in contrast to their focus on a single Midwestern city. Differences in the proportion of AfricanAmericans in North Carolina (21.5\% for the state versus $12.6 \%$ for the US) coupled with socioeconomic differences could have contributed to a teen mother sample of greater or lesser diversity than research samples from other regions of the country. Further exploration of birth outcome disparities therefore need to be considered according to the geographic characteristics for each study sample.

Contrary to other previous study results $[5,6]$, no significant differences were found in PTB between younger and older teens for the overall sample. In addition, racial disparities persisted regardless of age group. The finding in the bivariate analyses of the highest disparities in PTB rates between high income African-American and White teens younger than age 17 is noteworthy. Nevertheless, the racial differences in PTB odds remained significant in the multilevel analyses in context of maternal age, and racial and socioeconomic differences in PTB did not vary significantly by maternal age. Differences between study findings could stem from this study's categorization of maternal age groups. Although the age cutoff was based on Institute of Medicine reports that identified mothers younger than 17 as having higher rates of adverse birth outcomes $[1,2]$, other studies have found younger teen mothers (those younger than 15) may have even higher rates of adverse outcomes than teen mothers age 15 and older $[5,46]$. Taking all results in consideration from this study, African-American teen mothers are more likely than White teen moms to experience PTB regardless of their age group. Our findings suggest that younger maternal age does not sufficiently explain racial disparities among teen mothers whereas socioeconomic circumstances may be more important to consider in examining these racial disparities. Few studies explored birth outcome disparities between age groups of teen mothers in context of socioeconomic factors [8]; therefore, future studies should further examine racial disparities in PTB outcomes between age groups in other study samples.

Future studies should also explore other psychological and social factors that may explain racial disparities in PTB, such as disparities in maternal stress, interpersonal factors, and social context. For example, maternal stress is related to birth outcomes [47], and African-American mothers may experience different types of stress during pregnancy compared to other mothers [48]. Maternal stressors for AfricanAmerican teen mothers may include sexual coercion and intimate partner violence; these stressors are higher among African-American teen females compared to the national average for teens $[49,50]$. African-American teens of higher socioeconomic status also might gain a lower mental health benefit from their socioeconomic level than their White peers [51], which could also contribute to higher stress levels. In addition, differences in social support during pregnancy, particularly support from infants' fathers [52], may explain the racial disparities in birth outcomes. Overall, investigating associations between disparities in these individual, interpersonal, and social factors and disparities in birth outcomes could identify points of intervention, such as providing tailored community support in these areas for AfricanAmerican teen mothers during pregnancy.

Given the findings from this study, future prenatal and preconception health interventions may need to expand outreach in prenatal education and support to include more African-American teens of higher socioeconomic status. For example, these mothers may benefit from the use of alternate prenatal care models and community pregnancy support programs that have successfully improved birth outcomes for young African-American mothers of lower socioeconomic environments [53-56]. From a life course perspective, the current findings could also indicate that African-American teens of all socioeconomic levels should be considered highrisk for preconception health interventions. Because of the predominant intervention focus on economically disadvantaged mothers, limited research is available on benefits for African-American mothers from higher socioeconomic environments from these interventions. Further research is therefore needed on assessing the reach and effectiveness of current prenatal and preconception interventions for higher income African-American teen mothers.

This study had several limitations. First, only one demographic self-reported variable was used to assess racial identity. Quantitative interactions that include maternal race as a demographic variable to explore intersections generally provide limited understanding at the descriptive level of how racial disparities in health outcomes occur [57]. Warner [58] 
cautioned against the use of "master categories" (i.e., race) that might lead to stereotypical interpretations of results. Future studies could directly assess race-related maternal stressors, such as racial discrimination and inequity, which could explain racial disparities in birth outcomes among teen mothers. In particular, teens who experience multiple forms of racial discrimination may be at the greatest risk of poor health outcomes [59].

Second, limited information was available on several potential factors related to birth outcomes. Because of limited data available for all mothers in the 2010-11 cohorts, the authors did not control for other factors associated with preterm birth such as other demographics, medical risks, and prenatal behaviors. Notably, separate analyses for another sample of North Carolina teen mothers found that racial disparities in birth outcomes remained significant and did not decrease when accounting for these factors [60]. To build on the findings from this study, future studies should explore whether the intersectional relationships between race and income remain when controlling for these factors.

Third, information was not available about the length of time that mothers lived at their current address. Previous research noted detrimental effects of long-term poverty on birth outcomes for African-American adult mothers that grew up in deprived neighborhoods $[9,61]$; therefore, future studies could explore whether residential tenure in deprived neighborhood environments for teen mothers. Future studies should also examine if intersectional relationships between maternal race and income continue or change over time in cohorts of teen mothers as these disparities could change based on changes in teen pregnancy over time. Although births to teen mothers have decreased overall in the US $[12,28]$, births among White teen mothers decreased at a sharper rate than births among African-American teen mothers. As a result, the possibility exists that disparities identified in this study could change over time. As another future direction in research, studies can build on previous studies on adult mothers' pregnancy outcomes $[62,63]$ that examined population time trends in how social and economic factors are associated with preterm birth outcomes among teen mothers.

Finally, this study only used neighborhood income to operationalize socioeconomic status because household income information was not available from birth records. As a result, the impact of discrepancies between teens' household income and neighborhood median income could not be evaluated. African-American teen mothers who live in households with lower incomes than their neighborhood peers may have a higher risk of adverse outcomes because their families may lack the necessary financial resources, and their high income neighborhoods (with a lower ratio of African-American families) may provide little social support. Another consideration in using census income data stems from socioeconomic differences between North Carolina and other states. North Carolina's median household income was lower than the national average during 2010-2011 (\$46,291 versus $\$ 52,762$ ) [29], and this difference could indicate that teens in this sample could have circumstances of more economic distress than other areas in the country. Despite these considerations, using census income data to operationalize socioeconomic status allowed this study to build on previous research that found significant associations between neighborhood context and health outcomes [47, 64, 65].

Overall, this study contributes to the limited examinations of neighborhood factors related to PTB disparities among teen mothers. This study also exemplifies an intersectional approach for examining health outcomes among a statewide sample of teen mothers using vital records data for future studies. Intersectional approaches could enhance efforts to ameliorate racial disparities in PTB for teen populations. Continued exploration of disparities can provide critical information for development of interventions that can reduce disparities [66], and the findings from the current study justify further exploration of these disparities for the benefits of improvement of perinatal services and preconception health programs, improving birth outcomes, and reducing disparities among teen mothers.

\section{Conflict of Interests}

The authors declare that there is no conflict of interests regarding the publication of this paper.

\section{Acknowledgment}

The project described was supported, in part, by Award no. T32HD049302 from the National Institute of Child Health and Human Development. The content is solely the responsibility of the authors and does not necessarily represent the official views of the National Institute of Child Health and Human Development or the National Institutes of Health.

\section{References}

[1] Institute of Medicine Committee on Study the Prevention of Low Birth Weight, Preventing Low Birthweight, National Academies Press, Washington, DC, USA, 1985.

[2] Institute of Medicine Committee on Understanding Premature Birth and Assuring Healthy Outcomes Board on Health Sciences Policy, Preterm Birth: Causes, Consequences, and Prevention, National Academies Press, Washington, DC, USA, 2007.

[3] T. J. Mathews and M. F. MacDorman, "Infant mortality statistics from the 2009 period linked birth/infant death data set," National Vital Statistics Reports, vol. 61, no. 8, pp. 1-27, 2013.

[4] P. A. Buescher and M. Mittal, "Racial disparities in birth outcomes increase with maternal age: recent data from North Carolina," North Carolina Medical Journal, vol. 67, no. 1, pp. 1620, 2006.

[5] W. M. Gilbert, D. Jandial, N. T. Field, P. Bigelow, and B. Danielsen, "Birth outcomes in teenage pregnancies," The Journal of Maternal-Fetal and Neonatal Medicine, vol. 16, no. 5, pp. 265-270, 2004.

[6] X.-K. Chen, S. W. Wen, N. Fleming, K. Demissie, G. G. Rhoads, and M. Walker, "Teenage pregnancy and adverse birth outcomes: a large population based retrospective cohort study," International Journal of Epidemiology, vol. 36, no. 2, pp. 368373, 2007.

[7] C. R. Eure, M. K. Lindsay, and W. L. Graves, "Risk of adverse pregnancy outcomes in young adolescent parturients in an 
inner-city hospital," The American Journal of Obstetrics and Gynecology, vol. 186, no. 5, pp. 918-920, 2002.

[8] B. P. Markovitz, R. Cook, L. H. Flick, and T. L. Leet, "Socioeconomic factors and adolescent pregnancy outcomes: distinctions between neonatal and post-neonatal deaths?" BMC Public Health, vol. 5, article 79, 2005.

[9] J. W. Collins Jr., J. Wambach, R. J. David, and K. M. Rankin, "Women's lifelong exposure to neighborhood poverty and low birth weight: a population-based study," Maternal and Child Health Journal, vol. 13, no. 3, pp. 326-333, 2009.

[10] A. Lhila and S. Long, "What is driving the black-white difference in low birthweight in the US?" Health Economics, vol. 21, no. 3, pp. 301-315, 2012.

[11] D. Kim and A. Saada, "The social determinants of infant mortality and birth outcomes in western developed nations: a cross-country systematic review," International Journal of Environmental Research and Public Health, vol. 10, no. 6, pp. 2296-2335, 2013.

[12] J. A. Martin, B. E. Hamilton, S. J. Ventura, M. J. K. Osterman, and T. J. Mathews, "Births: final data for 2011," National Vital Statistics Reports, vol. 62, no. 1, pp. 1991-2011, 2013.

[13] A. S. Madkour, E. W. Harville, and Y. Xie, "Neighborhood disadvantage, racial concentration and the birthweight of infants born to adolescent mothers," Maternal and Child Health Journal, vol. 18, no. 3, pp. 663-671, 2014.

[14] S. N. Partington, D. L. Steber, K. A. Blair, and R. A. Cisler, "Second births to teenage mothers: risk factors for low birth weight and preterm birth," Perspectives on Sexual and Reproductive Health, vol. 41, no. 2, pp. 101-109, 2009.

[15] M. I. Bengiamin, J. A. Capitman, and M. B. Ruwe, "Disparities in initiation and adherence to prenatal care: impact of insurance, race-ethnicity and nativity," Maternal and Child Health Journal, vol. 14, no. 4, pp. 618-624, 2010.

[16] J. L. Cummings and P. B. Jackson, "Race, gender, and SES disparities in self-assessed health, 1974-2004," Research on Aging, vol. 30, no. 2, pp. 137-167, 2008.

[17] P. B. Jackson and D. R. Williams, "The intersection of race, gender, and SES: health paradoxes," in Gender, Race, Class, and Health: Intersectional Approaches, A. J. Schulz and and L. Mullings, Eds., pp. 131-155, Jossey-Bass, San Francisco, Calif, USA, 2006.

[18] S. R. Notaro, "Health disparities in African American maternal and child health," in Health Disparities Among Under-Served Populations: Implications for Research, Policy and Praxis, S. R. Notaro, Ed., pp. 121-133, Emerald Group Publishing Limited, 2012.

[19] E. K. Seaton, C. H. Caldwell, R. M. Sellers, and J. S. Jackson, "An intersectional approach for understanding perceived discrimination and psychological well-being among African American and caribbean black youth," Developmental Psychology, vol. 46, no. 5, pp. 1372-1379, 2010.

[20] L. Bowleg, "The problem with the phrase women and minorities: intersectionality-an important theoretical framework for public health," American Journal of Public Health, vol. 102, no. 7, pp. 1267-1273, 2012.

[21] L. Mullings, "Resistance and resilience: the sojourner syndrome and the social context of reproduction in cenral harlem," Transforming Anthropology, vol. 13, no. 2, pp. 79-91, 2005, Quotation from p. 79-80.

[22] U. Bronfenbrenner, "Ecological models of human development," in International Encyclopedia of Education, pp. 16431647, Elsevier Sciences, Oxford, UK, 1994.
[23] K. Glanz and D. B. Bishop, "The role of behavioral science theory in development and implementation of public health interventions," Annual Review of Public Health, vol. 31, pp. 399418, 2010

[24] K. R. McLeroy, D. Bibeau, A. Steckler, and K. Glanz, "An ecological perspective on health promotion programs," Health Education Quarterly, vol. 15, no. 4, pp. 351-377, 1988.

[25] J. S. Seng, W. D. Lopez, M. Sperlich, L. Hamama, and C. D. Reed Meldrum, "Marginalized identities, discrimination burden, and mental health: empirical exploration of an interpersonal-level approach to modeling intersectionality," Social Science and Medicine, vol. 75, no. 12, pp. 2437-2445, 2012.

[26] K. Jones-Vessey, Revisions to the North Carolina Birth Certificate and Their Impact on Tracking Maternal and Infant Health Data, Statistical Primer, NC State Center for Health Statistics, Raleigh, NC, USA, 2012.

[27] North Carolina State Center for Health Statistics, "North Carolina Live Birth Data," http://www.schs.state.nc.us/schs/ data/births/bd.cfm.

[28] J. A. Martin, B. E. Hamilton, S. J. Ventura et al., "Births: final data for 2010," National Vital Statistics Reports, National Center for Health Statistics, Hyattsville, Md, USA, 2012.

[29] U.S. Census Bureau, Profile of General Population and Housing Characteristics, U.S. Census Bureau, Washington, DC, USA, 2010.

[30] J. F. Culhane and I. T. Elo, "Neighborhood context and reproductive health," American Journal of Obstetrics \& Gynecology, vol. 192, no. 5, pp. S22-S29, 2005.

[31] T. Leventhal and J. Brooks-Gunn, "The neighborhoods they live in: the effects of neighborhood residence on child and adolescent outcomes," Psychological Bulletin, vol. 126, no. 2, pp. 309-337, 2000.

[32] J. W. Collins Jr., R. J. David, D. M. Simon, and N. G. Prachand, "Preterm birth among African American and white women with a lifelong residence in high-income Chicago neighborhoods: an exploratory study," Ethnicity and Disease, vol. 17, no. 1, pp. 113-117, 2007.

[33] IBM, IBM SPSS Statistics for Windows, Version 21.0, IBM, Armonk, NY, USA, 2012.

[34] S. W. Hinze, J. Lin, and T. E. Andersson, "Can we capture the intersections? Older black women, education, and health," Women's Health Issues, vol. 22, no. 1, pp. e91-e98, 2012.

[35] L. McCall, “The complexity of intersectionality," Signs, vol. 30, no. 3, pp. 1771-1800, 2005.

[36] J. F. Dawson, "Moderation in management research: what, why, when, and how," Journal of Business and Psychology, vol. 29, no. 1, pp. 1-19, 2014.

[37] J. Jaccard, Interaction Effects in Logistic Regression, Sage, Thousand Oaks, Calif, USA, 2001.

[38] K. J. Preacher, P. J. Curran, and D. J. Bauer, "Computational tools for probing interactions in multiple linear regression, multilevel modeling, and latent curve analysis," Journal of Educational and Behavioral Statistics, vol. 31, no. 4, pp. 437-448, 2006.

[39] S. W. Raudenbush and A. S. Bryk, Hierarchical Linear Models: Applications and Data Analysis Methods, Sage Publications, Thousand Oaks, Calif, USA, 2nd edition, 2002.

[40] A. H. Schempf, J. S. Kaufman, L. C. Messer, and P. Mendola, "The neighborhood contribution to black-white perinatal disparities: an example from two North Carolina Counties, 19992001," The American Journal of Epidemiology, vol. 174, no. 6, pp. 744-752, 2011. 
[41] P. J. Sparks and C. S. Sparks, "Socioeconomic position, rural residence, and marginality influences on obesity status in the adult Mexican population," International Journal of Population Research, vol. 2012, Article ID 757538, 13 pages, 2012.

[42] Scientific Software International, HLM 7.01, Scientific Software International, Skokie, Ill, USA, 2013.

[43] B. G. Tabachnick and L. S. Fidell, "Multilevel linear modeling," in Using Multivariate Statistics, Pearson Education, Upper Saddle River, NJ, USA, 2012.

[44] A. T. Geronimus, "Black/white differences in the relationship of maternal age to birthweight: a population-based test of the weathering hypothesis," Social Science and Medicine, vol. 42, no. 4, pp. 589-597, 1996.

[45] K. E. Pickett, J. W. Collins Jr., C. M. Masi, and R. G. Wilkinson, "The effects of racial density and income incongruity on pregnancy outcomes," Social Science and Medicine, vol. 60, no. 10, pp. 2229-2238, 2005.

[46] O. T. Malabarey, J. Balayla, S. L. Klam, A. Shrim, and H. A. Abenhaim, "Pregnancies in young adolescent mothers: a population-based study on 37 million births," Journal of Pediatric \& Adolescent Gynecology, vol. 25, no. 2, pp. 98-102, 2012.

[47] S. Nkansah-Amankra, K. J. Luchok, J. R. Hussey, K. Watkins, and X. Liu, "Effects of maternal stress on low birth weight and preterm birth outcomes across neighborhoods of South Carolina, 2000-2003," Maternal and Child Health Journal, vol. 14, no. 2, pp. 215-226, 2010.

[48] L. Rosenthal and M. Lobel, "Explaining racial disparities in adverse birth outcomes: unique sources of stress for Black American women," Social Science and Medicine, vol. 72, no. 6, pp. 977-983, 2011.

[49] A. C. Kennedy, D. Bybee, S. J. Kulkarni, and G. Archer, "Sexual victimization and family violence among urban African American adolescent women: do violence cluster profiles predict partner violence victimization and sex trade exposure?" Violence Against Women, vol. 18, no. 11, pp. 1319-1338, 2012.

[50] D. E. Howard, K. J. Debnam, and M. Q. Wang, "Ten-year trends in physical dating violence victimization among US adolescent females," Journal of School Health, vol. 83, no. 6, pp. 389-399, 2013.

[51] B. Jackson and E. Goodman, "Low social status markers: do they predict depressive symptoms in adolescence?" Race and Social Problems, vol. 3, no. 2, pp. 119-128, 2011.

[52] A. P. Alio, A. K. Mbah, R. A. Grunsten, and H. M. Salihu, "Teenage pregnancy and the influence of paternal involvement on fetal outcomes," Journal of Pediatric and Adolescent Gynecology, vol. 24, no. 6, pp. 404-409, 2011.

[53] M. A. Grady and K. C. Bloom, "Pregnancy outcomes of adolescents enrolled in a CenteringPregnancy program," Journal of Midwifery \& Women's Health, vol. 49, no. 5, pp. 412-420, 2004.

[54] K. J. Gruber, S. H. Cupito, and C. F. Dobson, "Impact of Doulas on healthy birth outcomes," The Journal of Perinatal Education, vol. 22, no. 1, pp. 49-58, 2013.

[55] J. R. Ickovics, T. S. Kershaw, C. Westdahl, U. Magriples, Z. Massey, and H. Reynolds, "Group prenatal care and perinatal outcomes: a randomized controlled trial," Obstetrics and Gynecology, vol. 110, no. 2, pp. 330-339, 2007.

[56] J. R. Ickovics, T. S. Kershaw, C. Westdahl et al., "Group prenatal care and preterm birth weight: results from a matched cohort study at public clinics," Obstetrics and Gynecology, vol. 102, no. 5, pp. 1051-1057, 2003.

[57] E. R. Cole, "Intersectionality and research in psychology," The American Psychologist, vol. 64, no. 3, pp. 170-180, 2009.
[58] L. R. Warner, "A best practices guide to intersectional approaches in psychological research," Sex Roles, vol. 59, no. 5-6, pp. 454-463, 2008.

[59] E. A. Grollman, "Multiple forms of perceived discrimination and health among adolescents and young adults," Journal of Health and Social Behavior, vol. 53, no. 2, pp. 199-214, 2012.

[60] S. L. Coley and R. E. Aronson, "Exploring birth outcome disparities and the impact of prenatal care utilization among North Carolina teen mothers," Women's Health Issues, vol. 23, no. 5, pp. e287-e294, 2013.

[61] C. Love, R. J. David, K. M. Rankin, and J. W. Collins Jr., "Exploring weathering: effects of lifelong economic environment and maternal age on low birth weight, small for gestational age, and preterm birth in African-American and white women," The American Journal of Epidemiology, vol. 172, no. 2, pp. 127-134, 2010.

[62] V. K. Pillai, A. Maleku, and F. Wei, "Maternal mortality and female literacy rates in developing countries during 19702000: a latent growth curve analysis," International Journal of Population Research, vol. 2013, Article ID 163292, 11 pages, 2013.

[63] C. Varea, C. Bernis, and A. G. González, "Maternal characteristics and temporal trends in birth outcomes: comparison between Spanish and migrant mothers," International Journal of Population Research, vol. 2012, Article ID 412680, 8 pages, 2012.

[64] L. C. Messer, L. C. Vinikoor-Imler, and B. A. Laraia, "Conceptualizing neighborhood space: consistency and variation of associations for neighborhood factors and pregnancy health across multiple neighborhood units," Health \& Place, vol. 18, no. 4, pp. 805-813, 2012.

[65] S. Nkansah-Amankra, A. Dhawain, J. R. Hussey, and K. J. Luchok, "Maternal social support and neighborhood income inequality as predictors of low birth weight and preterm birth outcome disparities: analysis of South Carolina pregnancy risk assessment and monitoring system survey, 2000-2003," Maternal and Child Health Journal, vol. 14, no. 5, pp. 774-785, 2010.

[66] P. A. Meyer, A. Penman-Aguilar, V. A. Campbell et al., "Conclusion and future directions: CDC health disparities and inequalities report-United States," Morbidity and Mortality Weekly Report. Surveillance Summaries, vol. 62, no. 3, pp. 184186, 2013. 

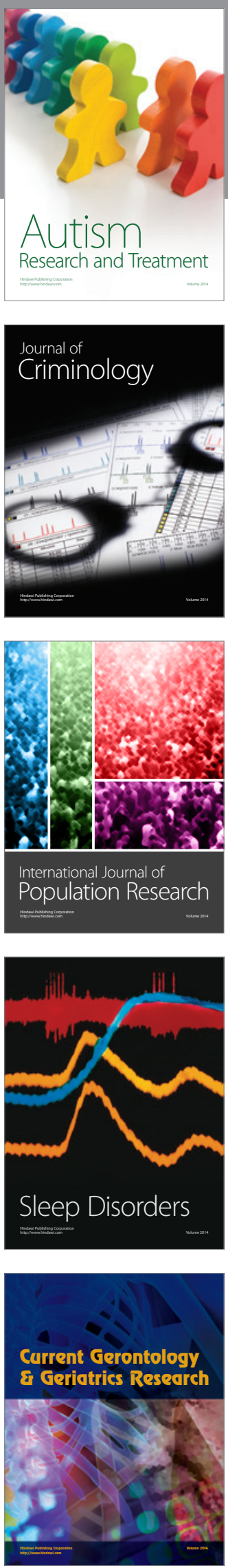
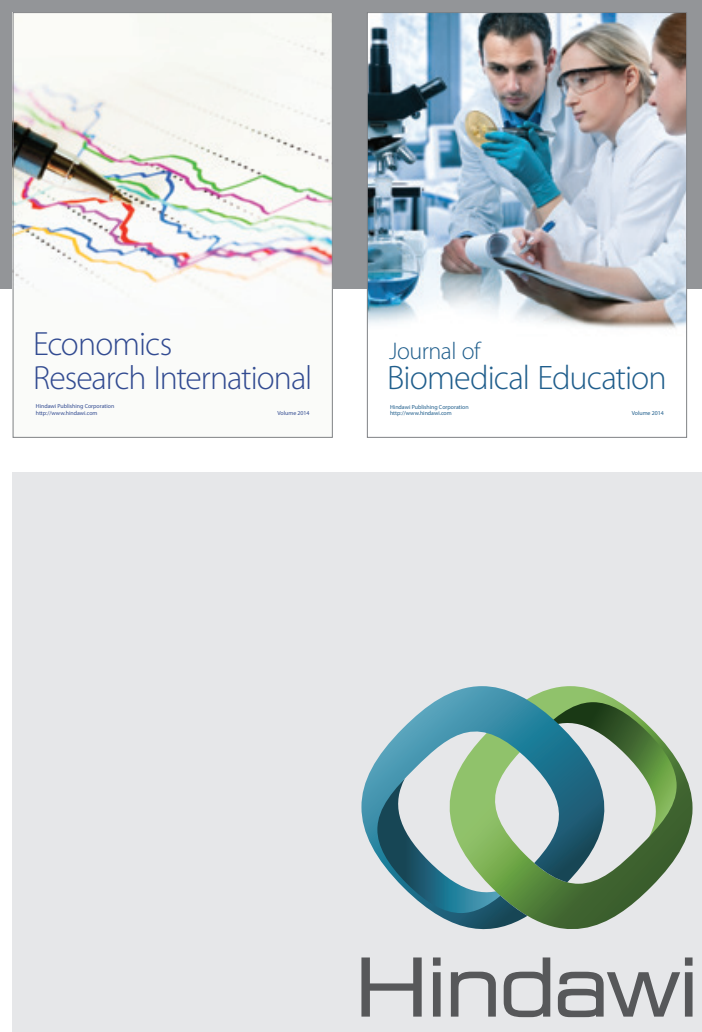

Submit your manuscripts at

http://www.hindawi.com
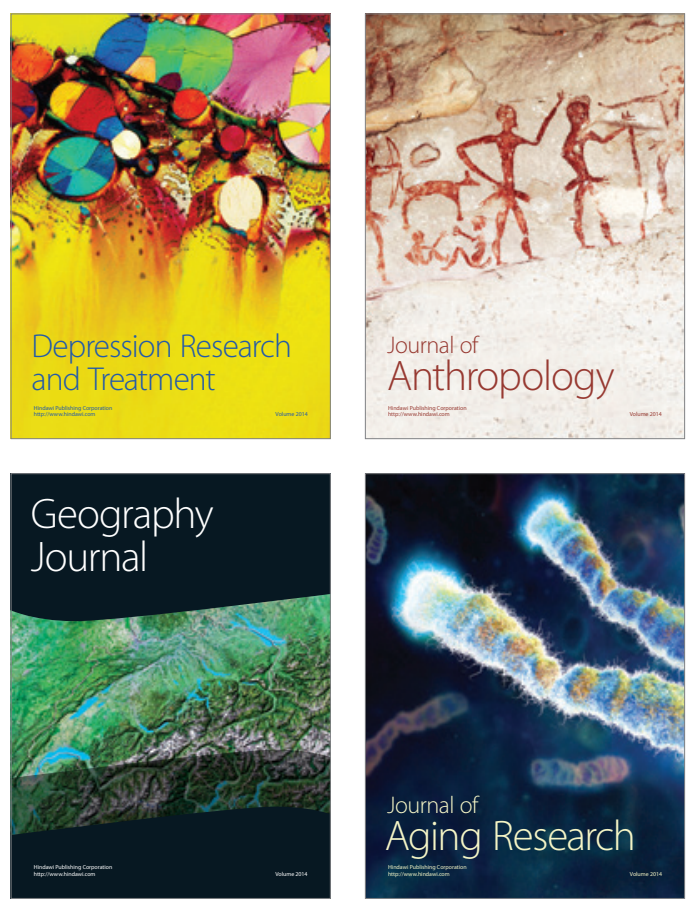
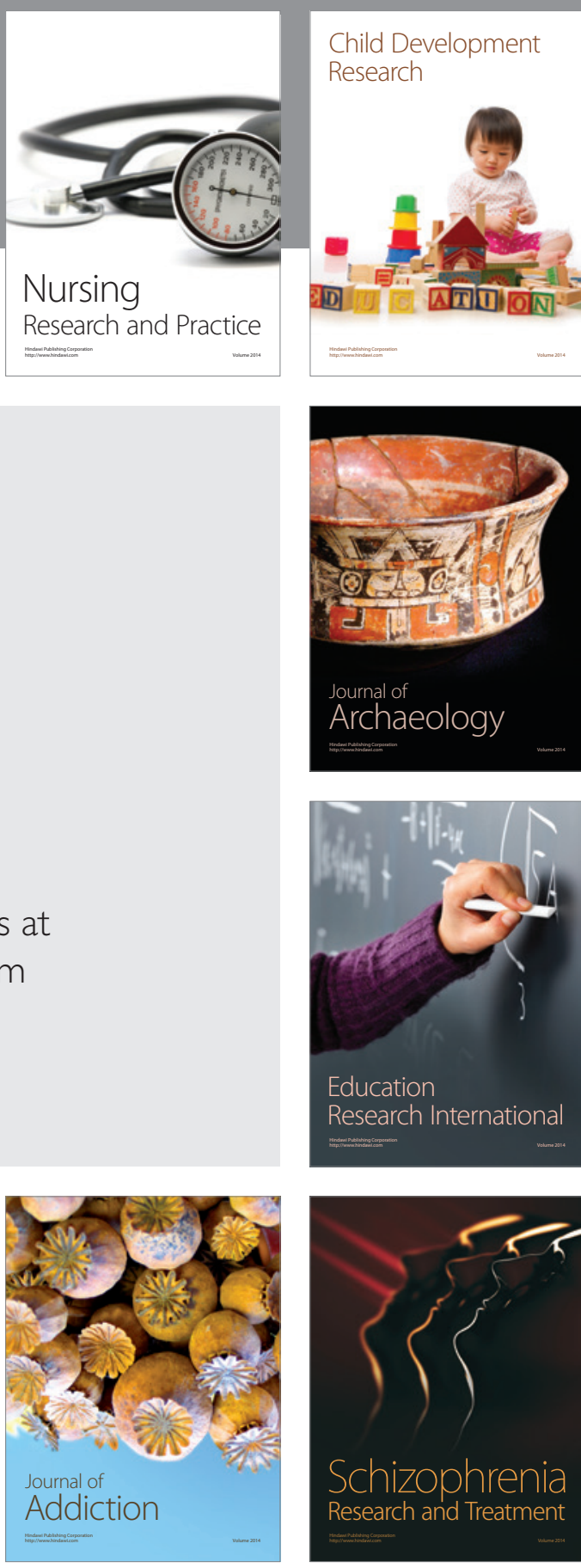

(D)
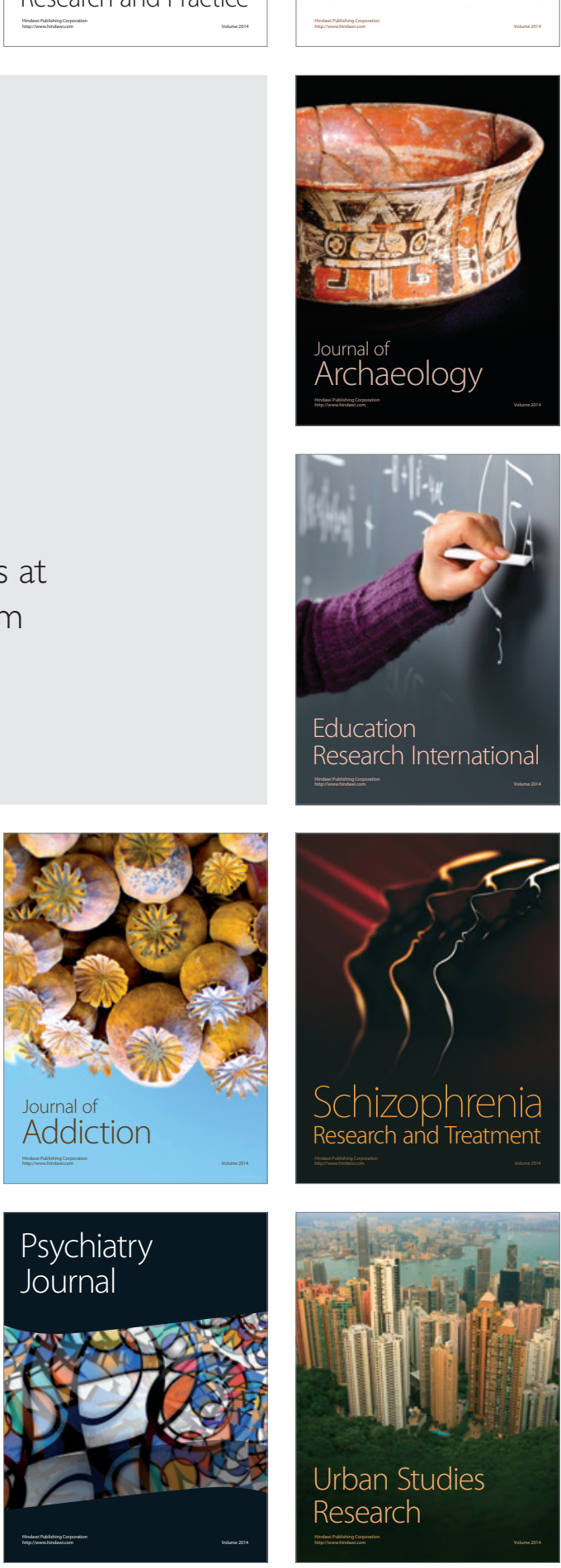